
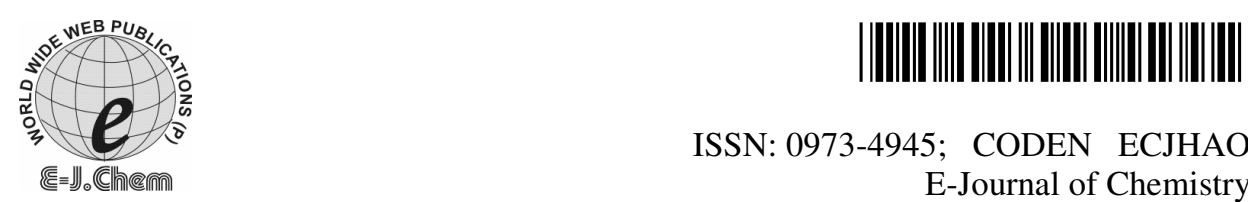

ISSN: 0973-4945; CODEN ECJHAO

http://www.e-journals.net

\title{
Evaluation of Excess Free Volume and Internal Pressure in Binary Mixtures of Methyl Methacrylate(MMA) with Alcohols
}

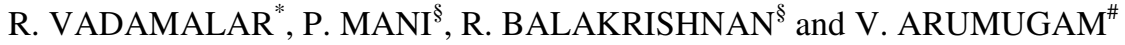 \\ *Department of Physics, \\ Marudhar Kesari Jain College, Vaniyambadi, Tamil Nadu, India. \\ ${ }^{\S}$ Department of Physics, \\ Hindustan University, Kelambakkam,India. \\ ${ }^{\#}$ Biophysics Lab, \\ Central Leather Research Institute, Adyar, Chennai, India. \\ vadamalarvnb@yahoo.co.in
}

Received 29 July 2008; Revised 24 September 2008; Accepted 28 September 2008

\begin{abstract}
Methyl methacrylate (MMA) is an important monomer attracting the attention of industrialists and scientists because of its various applications and reactivity. The knowledge of thermodynamic and transport properties of MMA in alcohols and other organic solvents is useful in industrial processes. Ultrasonic and viscometric parameters offer simple, easy and accurate ways for calculating several physical parameters which throw light on molecular interactions in solutions. In this paper, the interactions of two alcohols; tert-butanol and isobutanol with MMA are reported for the first time. Comparison has been made on the interactive nature of the two alcohols. Computation of free volume, internal pressure and excess free volume has been made for the entire concentration range. Existence of mesomeric effects of MMA is clearly seen and the role of structure of alcohols is observed.
\end{abstract}

Keywords: MMA, Ultrasonic velocity, Free volume, Internal pressure.

\section{Introduction}

Many engineering problems require quantitative data of the viscosity and density of the liquid mixtures. The physical properties and thermodynamic behaviour of polar and non polar mixtures have been studied for many reasons, one of the most important of which is that these properties provide information about molecular interactions. Methyl methacrylate (MMA) monomer is an excellent base material used in dentistry, ophthalmology and other 
industries. It has been studied widely by several researchers because of its varied applications, structure and its reactivity with organic solvents. From the structure point of view, $\mathrm{C}^{13}$ NMR and FTIR studies have been made by several workers ${ }^{1-6}$. Molecular interactions of MMA with several organic solvents ${ }^{7-10}$, alkanes ${ }^{11,12}$ hydrocarbons $^{13-15}$, alcohols ${ }^{16-18}$ and alkylamines and haloalkanes ${ }^{19}$ have been studied by several workers through excess property and thermo dynamical calculations. The free volume ${ }^{20}$ has been found to be an important property of liquid state and has been extensively applied to liquid and liquid mixtures. Several workers ${ }^{11,12,21-24}$ evaluated the free volume and internal pressure using different relations and discussed the intermolecular interactions on the basis of these parameters. In this report we have evaluated the free volume $\left(\mathrm{V}_{\mathrm{f}}\right)$, Internal pressure $\left(\Pi_{\mathrm{i}}\right)$ and excess free volume $\left(\mathrm{V}_{\mathrm{f}}^{\mathrm{E}}\right)$ at three different temperatures $(303,313,323 \mathrm{~K})$ in MMA + tert-butanol and MMA + iso-butanol systems.

\section{Experimental}

The MMA and alcohols were purchased from Lobochem, and were of Analar grade (purity greater than 99\%). The mixtures were prepared by mixing the measured volumes of the components in airtight stoppered brown bottles to minimize evaporation losses and light effects. Density measurements were made with an electronic balance (Mettler). The experimentally determined values of densities agreed well with literature data. The kinematic viscosities were measured by means of an Ubbelohde viscometer in a water bath with temperature stabilization (tolerance of $\pm 0.15 \mathrm{~K}$ ) provided with a thermostat. The viscometer was calibrated with double- distilled water. Ultrasonic velocities were measured using a crystal controlled variable path ultrasonic interferometer (Mittal Enterprises, New Delhi) operating at a frequency of $1 \mathrm{MHz}$. In all, the accuracy of the determined values of density, viscosity and ultrasonic velocity works out to be $\pm 0.0001 \mathrm{gm} / \mathrm{cm}^{3}, \pm 0.0001 \mathrm{mPa}-\mathrm{s}$ and $\pm 0.2 \mathrm{~m} / \mathrm{s}$ respectively.

\section{Theory}

The standard relationship for finding the internal pressure $\left(\pi_{\mathrm{i}}\right)$ and free volume $\left(\mathrm{V}_{\mathrm{f}}\right)$ and the excess free volume $\left(\mathrm{V}_{\mathrm{f}}^{\mathrm{E}}\right)$ respectively ${ }^{25}$ are given in Eqs. (1), (2) and (3) respectively. Eq. (1) is based on one dimensional analysis of the situation when an ultrasonic wave passes through a liquid medium.

$$
\pi_{\mathrm{i}}=\operatorname{bRT}(\mathrm{K \eta} / \mathrm{U})^{1 / 2}\left(\rho^{2 / 3} / \mathrm{M}_{\mathrm{eff}}^{7 / 6}\right)
$$

where $\eta$ is the viscosity of the mixture which is to be found (m Pa-s), 'b' is the packing factor (1.78), $\mathrm{T}$ is the temperature of the mixture $(\mathrm{K}), \rho$ is the density of the mixture $\left(\mathrm{gm} / \mathrm{cm}^{3}\right), M_{\text {eff }}$ is effective mass of the mixture $\left(M_{1} X_{1}+M_{2} X_{2}\right), U$ is the ultrasonic velocity of the mixture $(\mathrm{m} / \mathrm{s}), \mathrm{R}$ is gas constant given as 8.314 Joule/mole $\mathrm{K}$ and $\mathrm{K}$ is the constant of value $4.28 \times 10^{9}$ independent of temperature. The free volume is given by:

$$
\mathrm{V}_{\mathrm{f}}=(\mathrm{M} \mathrm{U} / \mathrm{k} \eta)^{3 / 2}
$$

Where $\mathrm{M}$ is the molecular weight $(\mathrm{gm}), \mathrm{U}$ is the ultrasonic velocity $(\mathrm{m} / \mathrm{sec}), \mathrm{H}$ is the viscosity (m Pas-s), $\mathrm{K}$ is a constant equal to $4.28 \times 10^{9}$ independent of temperature, and $\mathrm{V}_{\mathrm{f}}$ is free volume, in millilitre per mole. The excess free volume is given by:

$$
\mathrm{V}_{\mathrm{f}}^{\mathrm{E}}=\mathrm{V}_{\mathrm{fm}}-\left(\mathrm{X}_{1} \mathrm{~V}_{\mathrm{f} 1}+\mathrm{X}_{2} \mathrm{~V}_{\mathrm{f} 2}\right)
$$

where $\mathrm{V}_{\mathrm{f}}{ }^{\mathrm{E}}$ is the excess free volume, $\mathrm{V}_{\mathrm{fm}}$ is the free volume of mixture, $\mathrm{V}_{\mathrm{f} 1}$ and $\mathrm{V}_{\mathrm{f} 2}$ are the free volumes of the pure components. $X_{1}$ and $X_{2}$ are the mole fractions of the components. All the three equations have been very widely used for liquids, mixtures and solutions. These equations have been used in this paper too. 


\section{Results and Discussion}

The measured values of $\rho, \eta$ and $u$ of the pure components are given in Table 1 . As seen, the density of MMA is greater than those of the alcohols. The velocity is found to follow the order

$$
\mathrm{U}_{\text {Isobutanol }}>\mathrm{U}_{\text {MMA }}>\mathrm{U}_{\text {tert-Butanol}} \text {. }
$$

The alcohols are more viscous than MMA. The variations of the quantities of all the components with the temperature follow the usual trend. All the three parameters $\rho, \eta$ and $u$ decrease with rise in temperature.

Table 1. Densities, viscosities and speeds of sound of the components of mixtures.

\begin{tabular}{|c|c|c|c|c|c|c|c|}
\hline \multirow[t]{2}{*}{ System } & \multirow[t]{2}{*}{$\begin{array}{l}\mathrm{T} \\
\mathrm{K}\end{array}$} & \multicolumn{2}{|c|}{$\begin{array}{c}\rho \\
\mathrm{gm} \mathrm{m}^{-3}\end{array}$} & \multicolumn{2}{|c|}{$\begin{array}{c}\eta \\
\mathrm{m} \mathrm{Pa}-\mathrm{s}\end{array}$} & \multicolumn{2}{|c|}{$\underset{\mathrm{ms}^{-1}}{\mathrm{u}}$} \\
\hline & & Exp. & Lit. & Exp. & Lit. & Exp. & Lit. \\
\hline \multirow[t]{3}{*}{ MMA } & 303 & 0.9323 & $\begin{array}{l}0.9317^{7} \\
0.9323^{18}\end{array}$ & 0.5311 & $0.5290^{26}$ & 1165 & \\
\hline & 313 & 0.9215 & $0.9209^{28}$ & 0.4501 & $0.453^{18}$ & 1133 & $1136^{28}$ \\
\hline & 323 & 0.9092 & $0.9084^{28}$ & 0.4331 & & 1108 & \\
\hline \multirow[t]{2}{*}{ tert-Butanol } & 303 & 0.7734 & $\begin{array}{l}0.7757^{31} \\
0.7762^{29}\end{array}$ & 4.324 & $4.312^{26}$ & 1110 & $\begin{array}{c}1114^{\mathrm{a}} \\
1104^{29}\end{array}$ \\
\hline & $\begin{array}{l}313 \\
323\end{array}$ & $\begin{array}{l}0.7637 \\
0.7529\end{array}$ & & $\begin{array}{c}2.6261 \\
1.417\end{array}$ & $1.421^{26}$ & $\begin{array}{l}1068 \\
1031\end{array}$ & \\
\hline \multirow[t]{2}{*}{ iso-Butanol } & 303 & 0.7935 & $0.7942^{31}$ & 3.4342 & & 1177 & $\begin{array}{l}1179^{31} \\
1172^{27}\end{array}$ \\
\hline & $\begin{array}{l}313 \\
323\end{array}$ & $\begin{array}{l}0.7756 \\
0.7529\end{array}$ & & $\begin{array}{l}2.6848 \\
2.0098\end{array}$ & & $\begin{array}{l}1152 \\
1127\end{array}$ & \\
\hline
\end{tabular}

\section{Internal pressure}

Table 2 gives the values of internal pressure of the two binary mixtures for different temperatures. The internal pressure is a sensitive parameter to solute-solvent interactions, and reflects both the attractive and repulsive molecular interactions.

Table 2. Internal pressure of MMA + alcohols.

\begin{tabular}{cccc}
\hline \multirow{2}{*}{$\begin{array}{c}\text { Mole fraction of } \\
\text { MMA }\end{array}$} & \multicolumn{3}{c}{ Internal Pressure, atm } \\
\cline { 2 - 4 } $\mathrm{X}_{1}$ & \multicolumn{3}{c}{ Temperature, $\mathrm{K}$} \\
\cline { 2 - 4 } 0.0000 & MMA + tert-Butanol \\
0.0902 & 10171 & 8279 & 323 \\
0.1824 & 7755 & 7335 & 6331 \\
0.2767 & 5623 & 5075 & 4853 \\
0.3730 & 5201 & 4522 & 4320 \\
0.4716 & 4418 & 3789 & 3881 \\
0.5724 & 3975 & 3662 & 3525 \\
0.6756 & 3736 & 3397 & 3420 \\
0.7812 & 3547 & 3211 & 3216 \\
0.8893 & 3354 & 3059 & 3064 \\
1.0000 & 3144 & 2889 & 2905 \\
& 2830 & 2806 & 2819 \\
\hline
\end{tabular}




\begin{tabular}{cccc}
\multicolumn{4}{c}{ MMA + iso-Butanol } \\
\hline 0.0000 & 8955 & 8144 & 7209 \\
0.0881 & 7739 & 7325 & 6734 \\
0.1786 & 4809 & 4837 & 4718 \\
0.2715 & 4667 & 4561 & 4536 \\
0.3670 & 4433 & 4359 & 4419 \\
0.4652 & 3944 & 3910 & 4300 \\
0.5661 & 3560 & 3549 & 3733 \\
0.6699 & 3589 & 3378 & 3463 \\
0.7767 & 3545 & 3212 & 3290 \\
0.8867 & 3307 & 2981 & 3030 \\
1.0000 & 2830 & 2806 & 2819 \\
\hline
\end{tabular}

The internal pressure of the solutions decreases with concentration. The decrease in internal pressure of the solutions indicates that the addition of monomer (solute) decreases the cohesive forces of the solvent (alcohols) at all temperatures. The decrease is more prominent at lower concentrations of MMA for both the mixtures. The magnitude of $\Pi_{i}$ follows the order

$$
\text { MMA + iso-butanol > MMA + tert -butanol }
$$

The internal pressure of all the solutions decreases with temperature at all concentrations. As the temperature increases, the cohesive forces weaken and hence there is a fall in internal pressure. (Figure $1 \& 2$ )

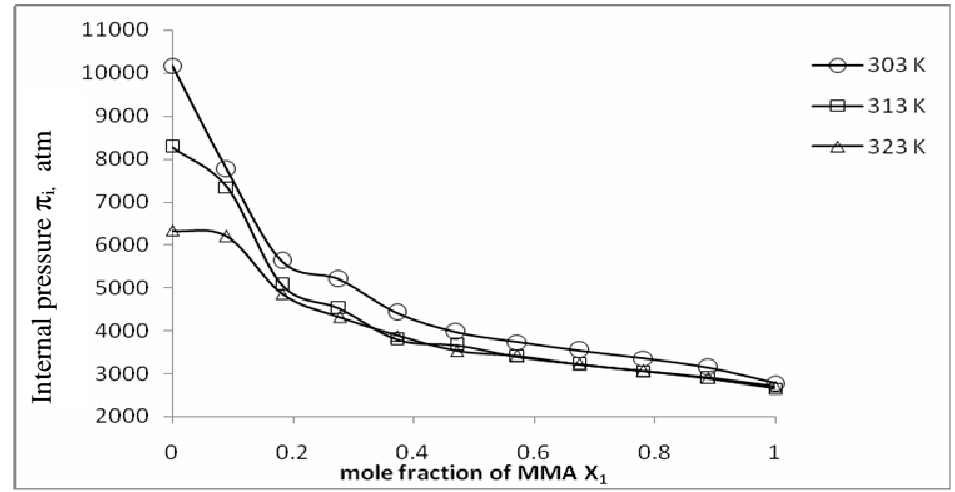

Figure 1. Internal pressure $v s$ mole fraction of MMA + tert-Butanol.

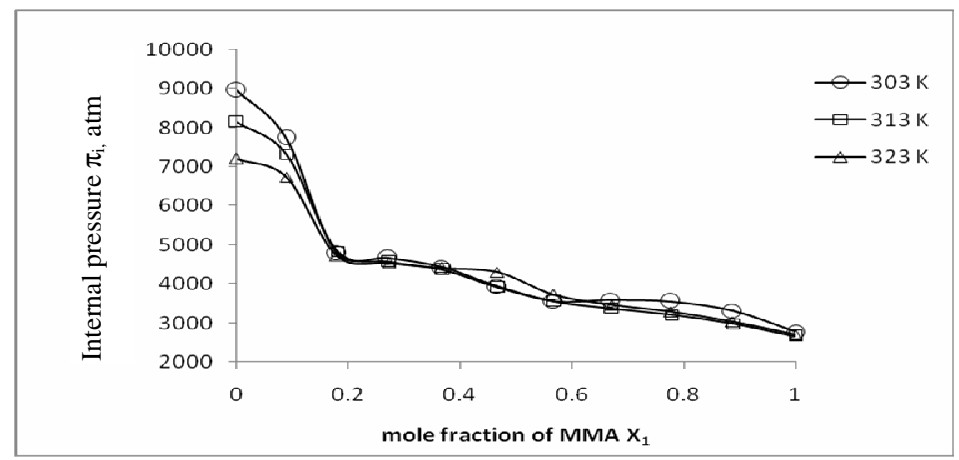

Figure 2. Internal pressure $v s$ mole fraction of MMA + iso-butanol. 


\section{Volumetric behaviour}

The computed values of free volume for the mixtures over the entire composition range at temperatures 303, 313 and $323 \mathrm{~K}$ are given in Table 3, along with the excess values $\left(\mathrm{V}_{\mathrm{f}}^{\mathrm{E}}\right)$. The free volume and the excess free volumes have been calculated using equations (2) and (3) respectively.

Table 3. Free volume $\left(V_{f}\right)$ and excess free volume $\left(V_{f}{ }^{E}\right)$ of MMA + alcohols.

\begin{tabular}{ccccccc}
\hline \multirow{2}{*}{$\begin{array}{c}\text { Mole fraction } \\
\text { MMA }\end{array}$} & \multicolumn{5}{c}{ Free volume $\left(\mathrm{V}_{\mathrm{f}}\right)$} & \multicolumn{5}{c}{ Excess free volume $\left(\mathrm{V}_{\mathrm{f}}^{\mathrm{E}}\right)$} \\
$n_{1}$ & $303 \mathrm{~K}$ & $313 \mathrm{~K}$ & $323 \mathrm{~K}$ & $303 \mathrm{~K}$ & $313 \mathrm{~K}$ & $323 \mathrm{~K}$ \\
\cline { 2 - 7 } & \multicolumn{6}{c}{ MMA + tert-Butanol } \\
0.0000 & 0.0094 & 0.0187 & 0.0447 & 0.0000 & 0.0000 & 0.0000 \\
0.0902 & 0.0207 & 0.0269 & 0.0480 & -0.0210 & -0.0309 & -0.0345 \\
0.1824 & 0.0538 & 0.0795 & 0.0989 & -0.0209 & -0.0182 & -0.0222 \\
0.2767 & 0.0671 & 0.1082 & 0.1340 & -0.0413 & -0.0304 & -0.0266 \\
0.3730 & 0.1042 & 0.1788 & 0.1819 & -0.0388 & -0.0016 & -0.0190 \\
0.4716 & 0.1410 & 0.1973 & 0.2367 & -0.0373 & -0.0258 & -0.0054 \\
0.5724 & 0.1670 & 0.2365 & 0.2505 & -0.0474 & -0.0302 & -0.0338 \\
0.6756 & 0.1965 & 0.2703 & 0.2887 & -0.0548 & -0.0411 & -0.0388 \\
0.7812 & 0.2239 & 0.3021 & 0.3230 & -0.0652 & -0.0550 & -0.0486 \\
0.8893 & 0.2689 & 0.3410 & 0.3642 & -0.0591 & -0.0629 & -0.0525 \\
1.0000 & 0.3676 & 0.4519 & 0.4630 & 0.0000 & 0.0000 & 0.0000 \\
\hline & & MMA & iso-Butanol & & \\
0.0000 & 0.0145 & 0.0203 & 0.0303 & 0.0000 & 0.0000 & 0.0000 \\
0.0881 & 0.0212 & 0.0268 & 0.0375 & -0.0243 & -0.0319 & -0.0310 \\
0.1786 & 0.0841 & 0.0901 & 0.1078 & 0.0066 & -0.0080 & 0.0001 \\
0.2715 & 0.0867 & 0.1023 & 0.1169 & -0.0236 & -0.0361 & -0.0312 \\
0.3670 & 0.0970 & 0.1120 & 0.1236 & -0.0471 & -0.0678 & -0.0659 \\
0.4652 & 0.1315 & 0.1475 & 0.1308 & -0.0472 & -0.0748 & -0.1012 \\
0.5661 & 0.1811 & 0.1882 & 0.1932 & -0.0333 & -0.0776 & -0.0824 \\
0.6699 & 0.1797 & 0.2127 & 0.2319 & -0.0713 & -0.0978 & -0.0886 \\
0.7767 & 0.1944 & 0.2477 & 0.2613 & -0.0943 & -0.1087 & -0.1054 \\
0.8867 & 0.2362 & 0.3020 & 0.3217 & -0.0914 & -0.1014 & -0.0924 \\
1.0000 & 0.3676 & 0.4519 & 0.4630 & 0.0000 & 0.0000 & 0.0000 \\
\hline
\end{tabular}

It is clear that the value of free volume of the both the mixtures (MMA + tert-Butanol, and MMA + iso-butanol) increases in a non linear manner as the temperature increases. Such behaviour of alcohols has also been observed by Arul et al ${ }^{30}$. It implies that when the temperature is increased, there is a tendency for the component molecules to move away from each other. This results in the reduction of cohesive forces leading to an increase in free volume. This may depend on the hydrogen bonding and size of the molecules, which in turn depend on the concentration of the hydroxyl solvent size and structure of the alcohol. As the concentration of alcohol decreases the hydrogen bonding also decreases. Therefore the solvent molecule occupies lesser volume and hence, an increase in free volume is observed for both the systems. However, as the temperature increases, hydrogen bonds break and hence the free volume increases with temperature. The increase in free volume of the mixtures is due to the breaking of hydrogen bonds in both MMA and hydroxyl groups 
present in alcohols. MMA is a conjugated system of single and double bonds, leading to polarisation. This gives a dipolar structure. Hence dipole-dipole attractions are possible between its molecules. While increasing temperature, the force of attraction between the molecules decreases, and therefore the free volume increases. This may be visualized as shown in the following scheme 1 .<smiles>C=C(C)C(=O)OC</smiles>

\section{Scheme 1}

The variations in $\mathrm{V}_{\mathrm{f}}$ and $\pi \mathrm{i}$ are almost similar for the entire concentration range for both the mixtures. Only a small variation is observed due to the isomeric forms of butanol system. At lower mole fractions of MMA (up to $\approx 0.40$ ), lower values of free volume are observed for MMA + tert-butanol mixture and higher values for MMA + iso-butanol mixture. In contrast, at higher mole fractions, an inverse trend are observed, i.e., the free volume is lower for MMA + iso-butanol mixture. This is due to the number of branches present in the $i s o$-butanol chain isomer. The same trend was also observed by Arul et $a l^{26}$ for the binary mixtures of benzene with tert-butanol and iso-butanol.

The excess free volume $\left(\mathrm{V}_{\mathrm{f}}^{\mathrm{E}}\right)$ values for both MMA + tert-Butanol, and MMA + isobutanol are completely negative which indicates that the intermolecular interactions present in both the systems are strong (Figure 3). However with rise in temperature, intermolecular interactions become weak when the solute and solvent are almost equal in concentration and for further increase in temperature the intermolecular interactions become totally weak for the whole range of concentration.

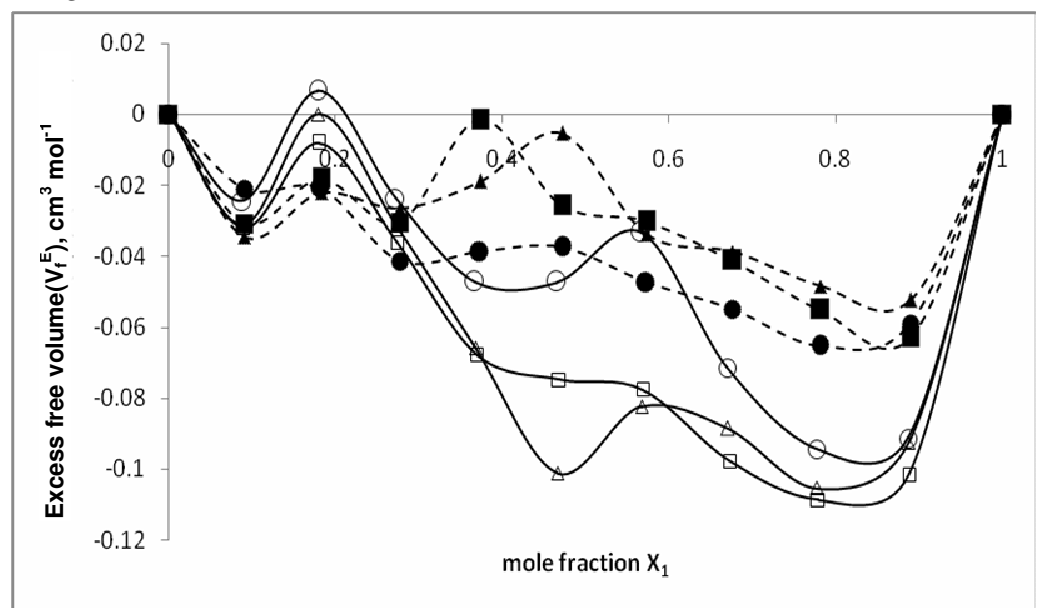

Figure 3. Excess free volume $v s$ mole fraction of MMA for MMA + tert-butanol and MMA + iso-butanol.

-O- iso-butanol-303 K, - - iso-butanol-313K, - $\Delta$ - iso-butanol-323K,

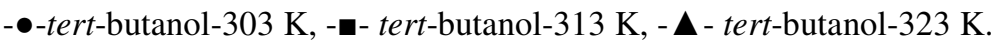


Similar observations - presence of weak interactions between the component molecules were found in benzene $+i s o$, sec, tert -butanl systems by Anwar Ali et $a l^{31}$. Dharmalingam $e t a l^{4}$. reported that the strength of the hydrogen bonding depends on the alkyl chain length of both the esters and the alcohols when they studied the hydrogen bond interaction between alkyl methacrylates (MMA,EMA,BMA) and six primary alcohols by FTIR and dielectric methods.

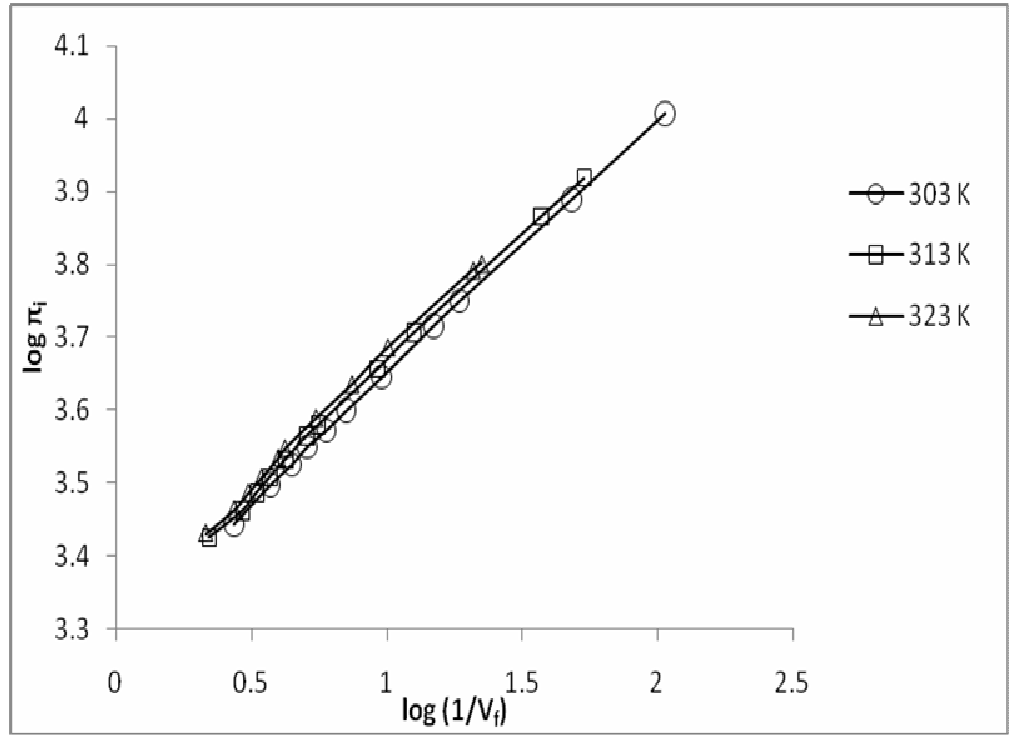

Figure 4. Plot of $\log \left(\pi_{\mathrm{i}}\right) v s \log \left(1 / \mathrm{V}_{\mathrm{f}}\right)$ for MMA +tert-butanol.

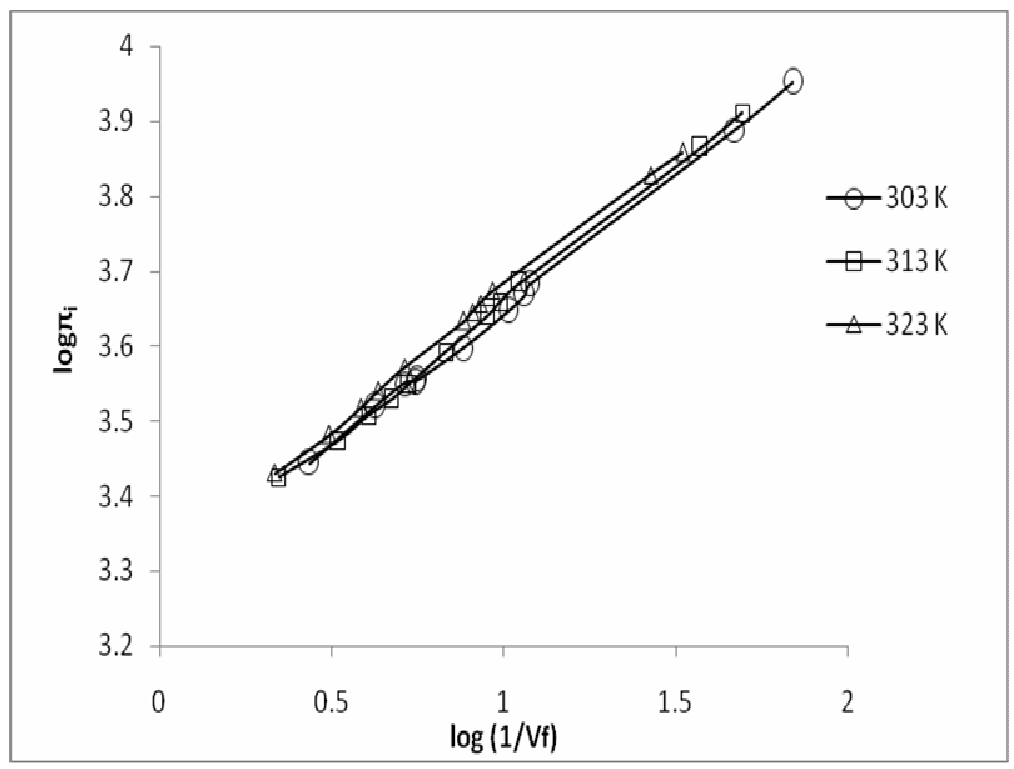

Figure 5. Plot of $\log (\pi \mathrm{i})$ vs $\log (1 / \mathrm{Vf})$ for MMA + iso-butanol. 
Lalitha et $a l .{ }^{32}$ studied the relation between $\mathrm{V}_{\mathrm{f}}$ and $\pi_{\mathrm{i}}$ at different temperatures and found that it obeys the equation $\pi_{\mathrm{i}} \mathrm{V}_{\mathrm{f}} \mathrm{X}=\mathrm{K}$ where $\mathrm{X}$ and $\mathrm{k}$ are constants. The same quantitative relationship between $V_{f}$ and $\pi_{i}$ was verified for the present systems of study. Plots of $\log \left(\pi_{\mathrm{i}}\right) v_{s} \log \left(1 / \mathrm{V}_{\mathrm{f}}\right)$ were perfectly linear for both mixtures at all three temperatures (Figures $4 \& 5$ ). This proves that the relation, $\pi_{\mathrm{i}} \mathrm{V}_{\mathrm{f}} \mathrm{x}=\mathrm{K}$ is true for MMA + alcohol mixtures too. The slope of the lines obtained is found to be close to $1 / 3$. The values of $\mathrm{K}$ are nearly the same for both the alcohols. There is a marginal increase in the $\mathrm{K}$ values with temperature at all concentrations. The values of $\mathrm{K}$ are given in Table 4

Table 4. Values of ' $\mathrm{K}$ ' from the equation $\pi_{\mathrm{i}} \mathrm{V}_{\mathrm{f}} \mathrm{X}=\mathrm{K}$ for binary mixtures at three different temperatures.

\section{Conclusions}

\begin{tabular}{cccc}
\hline & \multicolumn{3}{c}{ ' $\mathrm{K} '$} \\
\cline { 2 - 3 } $\mathrm{X}_{1}$ & $303 \mathrm{~K}$ & $313 \mathrm{~K}$ & $323 \mathrm{~K}$ \\
\hline \multicolumn{3}{c}{ MMA + tert-butanol } \\
0.0000 & 1965 & 1984 & 2017 \\
0.0902 & 1981 & 2004 & 2028 \\
0.1824 & 2010 & 2045 & 2071 \\
0.2767 & 2010 & 2035 & 2061 \\
0.3730 & 1993 & 2043 & 2073 \\
0.4716 & 1994 & 2045 & 2074 \\
0.5724 & 1989 & 2024 & 2055 \\
0.6756 & 2000 & 2008 & 2036 \\
0.7812 & 1981 & 1990 & 2021 \\
0.8893 & 1980 & 1963 & 2003 \\
1.0000 & 1951 & 1991 & 2032 \\
\hline \multicolumn{4}{c}{ MMA + iso-butanol } \\
0.0000 & 1957 & 1939 & 2004 \\
0.0881 & 1941 & 1933 & 2025 \\
0.1786 & 1978 & 1995 & 2088 \\
0.2715 & 1940 & 1971 & 2068 \\
0.3670 & 1918 & 1948 & 2056 \\
0.4652 & 1904 & 1933 & 2042 \\
0.5661 & 1928 & 1920 & 2045 \\
0.6699 & 1938 & 1911 & 2028 \\
0.7767 & 1969 & 1922 & 2013 \\
0.8867 & 1970 & 1919 & 2001 \\
1.0000 & 1940 & 1985 & 2026 \\
\hline
\end{tabular}

The present study on MMA + alcohol mixtures indicates the following conclusions:

1. Existence of specific interactions of strong magnitude is noticed in both the systems.

2. Mesomeric effects are predominantly noticed in the systems due to the presence of MMA molecules.

3. The nature of isomeric chain and the placement of the alcoholic group have sharp variations in the interaction mechanism.

4. The effects of the concentration of MMA as a solute and the temperature effects on hydrogen bonds in the system are clearly seen.

5. The role of hydrogen bonds and the structure of alcohols in interactions are observed. 
6. The negative excess values of free volume show specific interactions among unlike molecules. The lower values in the MMA + tert- butanol system indicate ideal mixing.

\section{References}

1. Yongsin Kim H James Harwood, Polymer, 2002, 43, 3229.

2. Shahzada Ahmad, Sharif Ahmad, Agrihotry S A, Bull Mater Sci., 2007, 30, 31.

3. Qing Liu, Jianping Zheng, and Danjun Fang, Spectros Lett., 2004, 37(2), 225.

4. Dharmalingam K, Ramachandran K and Sivagurunathan P, Physica., B, 2007, 392, 127.

5. Jainping Zheng, Qing Liu, Hui Zhang, and Danjun Fang Spectrochemica Acta Pt A, 2004, 60, 3119.

6. Sivagurunathan P, Dharmalingam K, and Ramachandran K, Spectrochemica Acta Pt A, 2006, 64, 127.

7. Jaime Wisniak, Isabel Villarreal, Rene D Peralta, Ramiro Infante, Gladis, and Homerosoto, J Chem Thermodyn., 2007, 39, 88.

8. John George, Sastry N V and Prasad D H L, Fluid Phase Equilibr., 2003, 214, 39.

9. Sastry N V, and Dave P N, Thermochemica Acta., 1996, 286, 119.

10. Luo B, Hamam B E M, Benson G C and BC-Y-Lu, J Chem Thermodyn., 1986, 18, 1043,

11. Sastry N V, Patel S R and Prasad D H L, Thermochemica Acta, 2000, 359, 169.

12. Sonia coriani, Asger Halkier, Dan Jonsson, Jurgen Gauss, Antonio Rizzo and Ove Christiansen, J Chem Phys., 2003,118, 7329.

13. Von Ratzch M T, E.Rickelt E and Rosner H Z, Phys Chem (Leipzig)., 1933, 262, 933.

14. Von Bonchardt D, Opel M, Radmacher H J and Von Ratzch M T, Z Phys Chem (Leipzig)., 1981, 262, 479.

15. C-Y-Lu B, Ishikawa T and Bensoen G C, J Chem Engg Data., 1990, 35, 331.

16. Sastry N V and Dave P N, Int J Thermophys., 1996, 17, 1289.

17. Sastry N V and Dave P N, Proc Indian Acad Chem Sci., 1997, 109, 211.

18. Sastry N V and Raj M M, Thermochimica Acta, 1995, 257, 39.

19. Dharmalingam K, Ramachandran $\mathrm{K}$ and Sivagurunathan $\mathrm{P}, J$ Zhejiang Univ SCIENCE, A, 2006, 7, 1928.

20. Lenard Jones and Devonshire A F, Proc Roy Soc., A, 1937, 163, 53.

21. Kilburn D, Dlubek G, Pointech J and Alam M A, J Polymer, 2006, 47, 7774.

22. Rakkapan C, J Chem Sci., 1989, 101, 429.

23. Okubo M, Fujii S, Maenaka H and Minami H, Colloid Polymer Sci., 2002, 280, 183.

24. Marcus Schmidt and Frans H J, Macromolecules., 2000, 33, 3879.

25. Suryanarayana C V and Kuppusami J, J Acoust Soc India, 1976, 4, 75.

26. CRC Handbook of Chemistry and Physics, ${ }^{\text {th }}$ Ed., 2007.

27. Pandey J D and Ashok Kumar, J pure Appl Ultrason., 1994, 16, 63,

28. Oswal S L, Patel B M, Patel A M and Ghael N Y, Fluid Phase Equlibr., 2003, 206, 313

29. Ali A and Nain A K, Pramana - J Phys., 2002, 58, 695.

30. Arul G, Jaafar Mohamad Suhaimi and Palaniappan L, Acta Phys- Chim Sin., 2008, 24, 41.

31. Anwar Ali, Anil Kumar Nain and Bhajan Lal, J Pure Appl Ultrason., 2004, 26, 40.

32. Lalitha V and Renuka devi K, J Pure Appl Ultrason., 2006, 28, 157. 


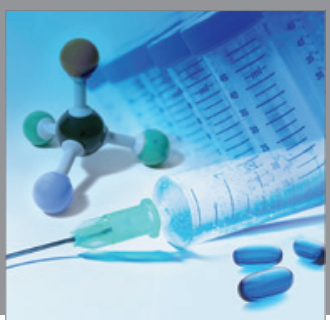

International Journal of

Medicinal Chemistry

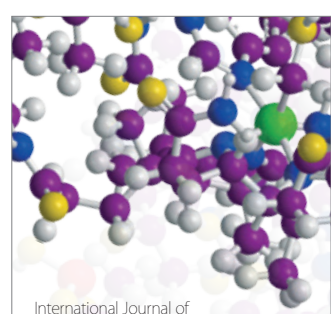

Carbohydrate Chemistry

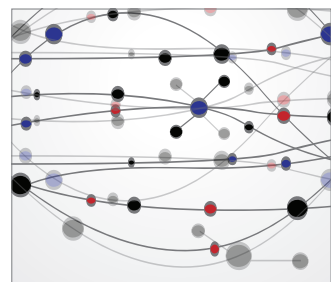

The Scientific World Journal
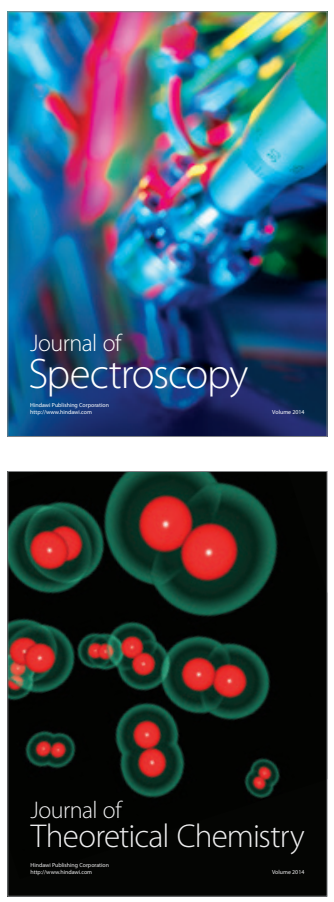
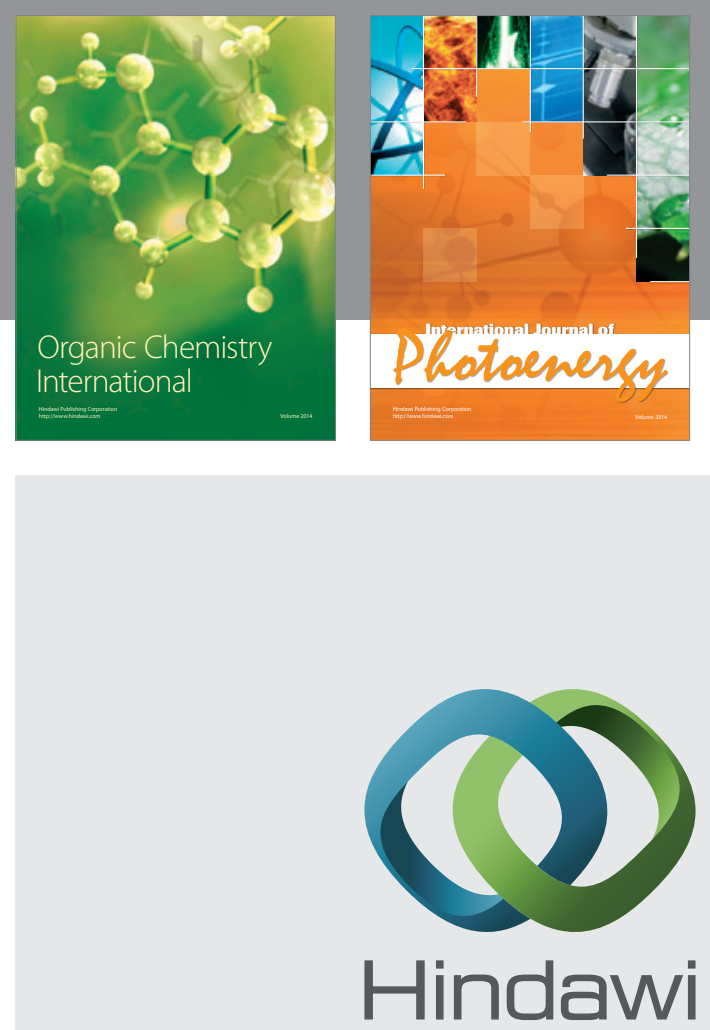

Submit your manuscripts at

http://www.hindawi.com
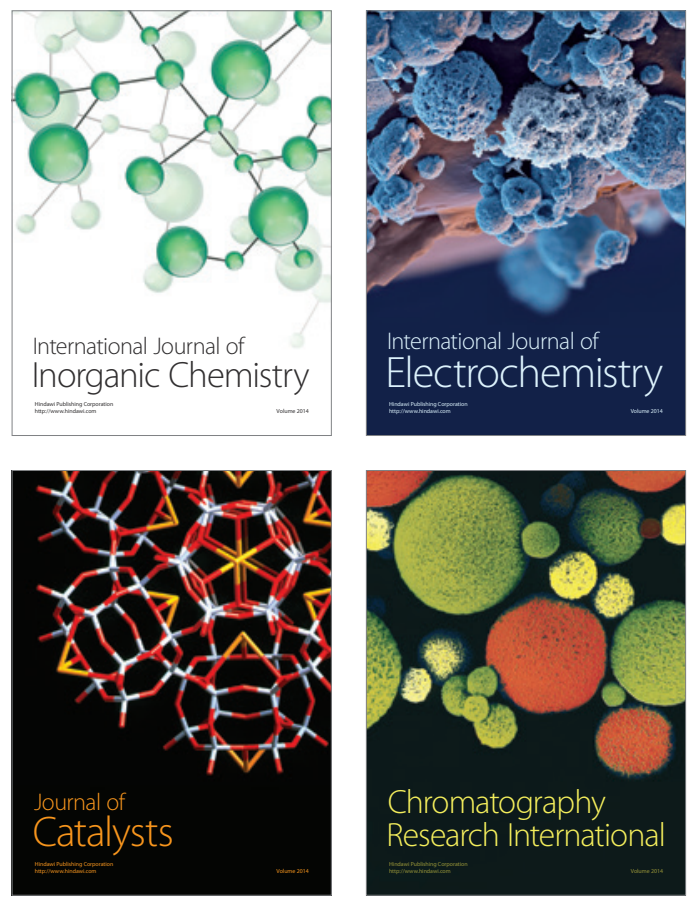
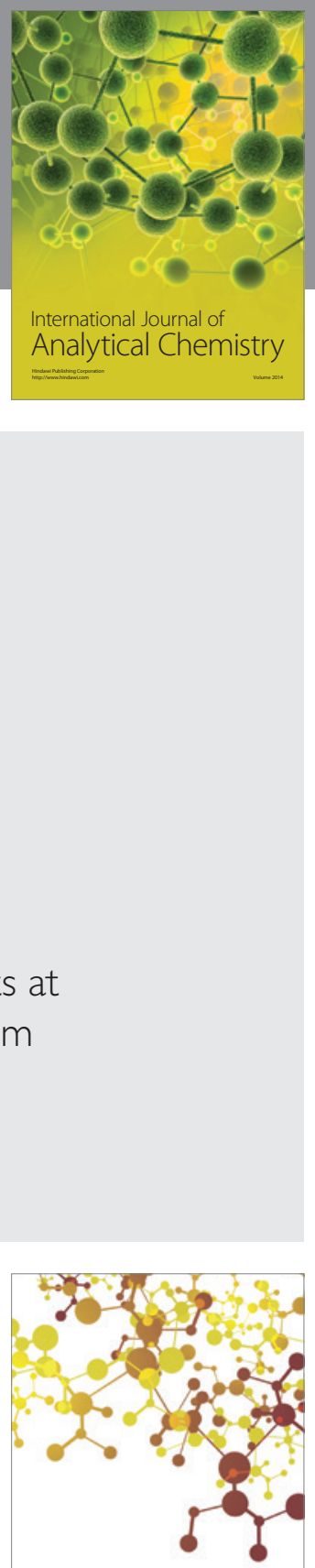

Journal of

Applied Chemistry
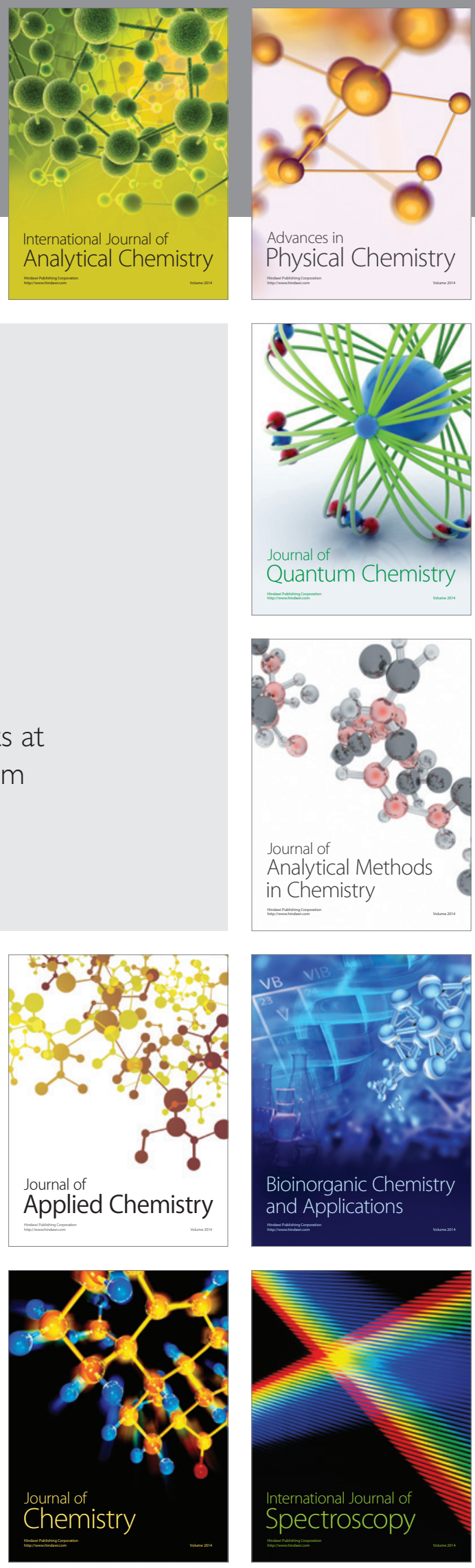